\title{
Apresentação e Avaliação do Jogo "Trânsito Consciente": Um Jogo Educacional Móvel de Auxílio à Conscientização sobre os Riscos de se Dirigir sob Efeito de Álcool
}

\author{
Vinícius Pereira Faria, Marcos Alves dos Santos, \\ Ana Carolina Gondim Inocêncio, Paulo Afonso Parreira Júnior
}

Curso de Bacharelado em Ciência da Computação/Instituto de Ciências Exatas e Tecnológicas, Universidade Federal de Goiás/Regional Jataí, Jataí/GO, Brasil

vinicius.pfaria@gmail.com, marcosdourado23@gmail.com. anacarolinaufgeufg.br, paulojuniorejatai.ufg.br

\begin{abstract}
Currently, it is visible the increasing of the number of vehicles on cities. Associated to this, unfortunately, there is the increasing of the amount of traffic accidents. The mix of "drinking and driving" is responsible for most of traffic fatal accidents. In this context, this paper presents an Android-based mobile educational game, called "Trânsito Consciente", whose focus is on awareness of people (just not drivers), about the risks of driving under the influence of alcohol. The evaluation carried out with the game showed good acceptance by thirty-eight evaluators regarding to the usefulness and the ease of use of the game.
\end{abstract}

Resumo. Atualmente, é visivel o crescimento da quantidade de veículos que transitam todos os dias nas ruas das cidades. Aliado a isto, infelizmente, há o aumento da quantidade de acidentes de trânsito. A mistura "álcool e direção”, além de ser responsável pela maioria dos acidentes de trânsito, provoca acidentes mais graves, com maior probabilidade de serem fatais. Neste artigo, apresenta-se um jogo educacional móvel para a plataforma Android, denominado "Trânsito Consciente", cujo enfoque está na conscientização dos indivíduos (não apenas motoristas), quanto aos riscos de se dirigir sob efeito de álcool. A partir da avaliação realizada com o jogo, notou-se boa aceitação por parte dos trinta e oito avaliadores, com respeito à utilidade do jogo e à facilidade de uso do mesmo.

\section{Introdução}

\subsection{Contextualização e Motivação}

Nos dias atuais, é visível o crescimento da quantidade de veículos que transitam todos os dias nas ruas das cidades. Paralelamente a isso, tem-se aumentado também a quantidade de acidentes de trânsito. Para tanto, a Assembleia-Geral da Organização das Nações Unidas (ONU) definiu o período de 2011 à 2020 como a "Década de Ações para a Segurança no Trânsito". Segundo o website "Maio Amarelo" (MaioAmarelo.com, 2015), divulgador do projeto "Maio Amarelo: Atenção pela Vida", um movimento em prol da segurança no trânsito, a iniciativa da ONU teve como base um estudo da Organização Mundial da Saúde (OMS), que contabilizou, em 2009, cerca de 1,3 milhão de mortes por acidente de trânsito em 178 países; o que significa, em média, 3.561 mortes por dia em todo o mundo, aproximadamente 2,5 mortes por minuto. 
Ainda segundo a OMS, acidentes de trânsito já são considerados a nona maior causa de mortes no mundo e são o primeiro responsável por mortes de pessoas na faixa de 15 a 29 anos de idade; o segundo na faixa de 5 a 14 anos; e o terceiro na faixa de 30 a 44 anos. Em termos financeiros, estes acidentes já representam um custo de US\$ 518 bilhões por ano ou um percentual entre $1 \%$ à $3 \%$ do Produto Interno Bruto (PIB) de cada país. O Brasil aparece em quinto lugar entre os países recordistas em mortes no trânsito. Tomando como base apenas a cidade de São Paulo, de acordo com o último relatório da Companhia de Engenharia de Tráfego de São Paulo - CET (CET, 2012), aproximadamente 27 mil acidentes de trânsito ocorreram no ano de 2012 nesta cidade, ou seja, aproximadamente 73 acidentes por dia. Destes acidentes, cerca de 1.204 tiveram vítimas fatais, o que significa 3,3 acidentes fatais/dia.

Segundo a ONU, a chave para a redução da mortalidade no trânsito é garantir que os estados-membros adotem leis que contemplem os cinco principais fatores de risco: dirigir sob o efeito de álcool, excesso de velocidade, não uso do capacete, do cinto de segurança e das cadeirinhas. No contexto deste artigo, chama-se a atenção para o fator de risco: dirigir sob o efeito de álcool. Segundo o Centro de Informações sobre Álcool e Saúde - CISA (CISA, 2015), um estudo retrospectivo realizado pelo Instituto Médico Legal (IML) da cidade de São Paulo mostrou que, de todas as autópsias dos casos de morte por acidentes de trânsito ocorridas no ano de 1999, aproximadamente $50 \%$ dos óbitos estavam associados ao uso de álcool.

Segundo Ravagnani (2010), o rumo para a minimização dos acidentes de trânsito e da taxa de mortalidade causada pela associação álcool e direção veicular está na educação, na legislação e na fiscalização. No que tange à legislação e à fiscalização, o Código de Trânsito Brasileiro (CTB) vem sofrendo mudanças para se adequar às tendências mundiais de controle de embriaguez no trânsito. Um exemplo disso é a Lei $n^{\circ}$ 12.760 (também conhecida como "lei seca"), sancionada em dezembro de 2012, que consiste em uma alteração no CTB para, além de aumentar o valor da multa administrativa, ampliar as possibilidades de provas da infração de dirigir sob a influência de álcool ou de qualquer substância psicoativa (CONTRAN, 2012).

Quanto à educação para o trânsito, estratégias preventivas de educação em escolas têm se mostrado eficientes na mudança de atitudes e na disseminação de informações sobre os riscos de se dirigir sob o efeito de álcool. A educação para o trânsito consiste em um conjunto de conhecimentos e métodos aplicados com o intuito de ensinar e convencer as pessoas a se comportarem de maneira apropriada no trânsito, para que a circulação de veículos e pedestres nas vias seja realizada com segurança, eficiência e comodidade (Ravagnani, 2010).

Um tipo de tecnologia educacional que têm despertado a atenção de professores e alunos nos últimos anos são os Jogos Educacionais Digitais (JEDs). Os jogos digitais, de forma geral, formam um dos ramos de entretenimento que mais cresce na indústria de software. Devido aos desafios, fantasias e diversão proporcionados pelos jogos, seus usuários conseguem passar longos períodos de tempo focados neles, apresentando um bom poder de concentração (Savi e Ulbricht, 2010). Na busca por atrair a atenção e comprometimento dedicados aos jogos por seus usuários, para as salas de aulas, o número de pesquisas sobre a junção entre entretenimento e ensino com jogos educacionais tem crescido bastante nos últimos anos (Savi e Ulbricht, 2010; Fernandes e Werner, 2009; Mitchell e Savill, 2004). JEDs podem ser considerados ferramentas 
computacionais ou eletrônicas utilizadas como material didático complementar no aprendizado em alguma área ou aprendizado de um conjunto de habilidades específicas (Annetta, 2010).

No mesmo sentido do crescimento do interesse por jogos digitais, estão a evolução tecnológica e o uso dos dispositivos eletrônicos móveis, como tablets, smartphones, entre outros. Estes dispositivos têm sido utilizados cada vez mais como meios para disponibilização de jogos digitais, devido a fatores como: (i) mobilidade oferecida aos seus usuários; (ii) redução dos preços para aquisição dos mesmos; (iii) quantidade de recursos oferecidos em um único aparelho, permitindo a execução de aplicativos e jogos cada vez mais sofisticados; e (iv) quantidade de recursos oferecidos aos desenvolvedores por meio dos kits de desenvolvimento; entre outros.

Segundo pesquisa realizada pelo Centro de Estudos sobre as Tecnologias da Informação e da Comunicação - CETIC.br (CETIC.br, 2012), o percentual de dispositivos móveis presentes nos domicílios brasileiros dobrou de 2011 para 2012. Ainda segundo o CETIC.br, em 2012 havia aproximadamente 140 milhões de aparelhos celulares no Brasil e $29 \%$ das atividades realizadas a partir destes aparelhos estavam relacionadas aos jogos digitais; esse número era maior do que o percentual de usuários que utilizavam o celular para acessar a Internet (CETIC.br, 2012).

\subsection{Objetivo}

Um problema que fica claro, a partir do que foi exposto anteriormente, é a "alta incidência de acidentes de trânsito relacionados à mistura de álcool e direção". Comentou-se ainda sobre algumas estratégias para atenuar este problema, a saber: elaboração de leis específicas, fiscalização e educação para o trânsito. No âmbito da educação, de um modo geral, o uso de JEDs tem se mostrado uma poderosa ferramenta de apoio ao ensino. Além disso, uma constatação interessante que pode ser extraída a partir dos dados apresentados pelo CETIC.br (2012) é que muitos dos usuários de dispositivos móveis o utilizam para jogar. Sendo assim, a construção de tecnologias que integrem o uso de dispositivos móveis aos jogos digitais pode ser potencialmente interessante no auxílio à conscientização da população com relação aos riscos de se dirigir sob efeito de álcool.

Levando em consideração os aspectos ressaltados anteriormente, o objetivo deste trabalho é auxiliar na conscientização da população em geral (não apenas de motoristas) quanto aos riscos de se dirigir sob efeito de álcool. Para isso, foi desenvolvido um Jogo Educacional Digital Móvel, denominado "Trânsito Consciente". Como objetivos específicos, tem-se: (i) promover uma maior compreensão nos indivíduos sobre os efeitos que o álcool pode causar no organismo humano, como perda de reflexo, visão embaçada e duplicada, entre outras coisas; (ii) permitir que o processo de educação para o trânsito se inicie antes mesmo de o indivíduo se tornar um motorista, o que pode auxiliar na formação de motoristas mais conscientes; (iii) atrair a atenção de crianças, adolescentes e jovens, que compõem boa parte dos usuários de jogos digitais, para o tema em questão; (iv) oferecer uma alternativa barata para divulgação e conscientização dos riscos de dirigir sob o efeito do álcool, em comparação a outras alternativas do mercado, como os simuladores de trânsito presentes nas autoescolas; e (v) ampliar a abrangência da proposta de conscientização, a saber, do jogo "Trânsito Consciente", permitindo que ele seja executado em dispositivos móveis. 
O restante deste artigo está organizado da seguinte forma: a Seção 2 apresenta o jogo "Trânsito Consciente", destacando as estratégias de implementação do mesmo, bem como sua funcionalidade. A Seção 3 destaca o planejamento, a execução e às ameaças à validade da avaliação realizada com indivíduos da sociedade, a respeito da facilidade de uso e utilidade do jogo "Trânsito Consciente". Por fim, a Seção 4 apresenta as considerações finais acerca deste trabalho, bem como as propostas para trabalhos futuros.

\section{O Jogo "Trânsito Consciente"}

\subsection{Estratégias de Implementação}

É importante ressaltar que o jogo "Trânsito Consciente" é livre e está disponível gratuitamente para download em: https://goo.gl/30B78c. Como ambiente de desenvolvimento, utilizou-se a engine para desenvolvimento de jogos Unity (http://unity3d.com/pt) e a plataforma Android (http://developer.android.com).

A engine Unity foi escolhida por ser robusta, possuir uma versão gratuita e permitir exportação dos jogos para a plataforma Android. A plataforma Android foi escolhida por apresentar papel de destaque no mercado, tanto pela quantidade significativa de dispositivos que a utilizam, como também por oferecer um kit de desenvolvimento rico, bem documentado e que oferece fácil acesso a vários recursos de hardware e software do dispositivo móvel.

\subsection{Apresentação do Jogo "Trânsito Consciente"}

O tema do jogo "Trânsito Consciente" é a "conscientização da população quanto aos riscos de se dirigir sob o efeito de álcool”. Quanto aos desafios, o jogador terá que controlar um veículo por uma autoestrada, compartilhada com outros veículos, utilizando o recurso de acelerômetro do dispositivo móvel (Figura $1-\mathrm{A}$ ). O acelerômetro é um dispositivo existente na maioria dos smartphones e tablets, que permite ao software do aparelho reconhecer a posição no espaço, na qual o usuário posicionou o aparelho. No contexto do jogo "Trânsito Consciente", o acelerômetro é utilizado para que o usuário consiga mover o veículo para a esquerda ou para a direita, conforme desejado.

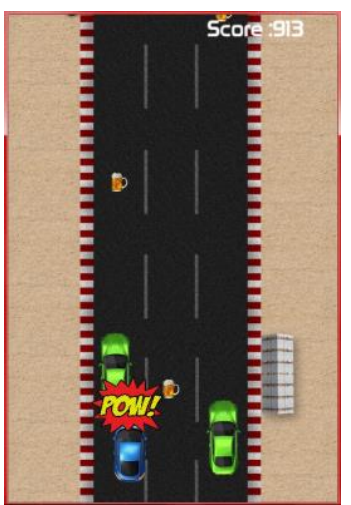

(A)

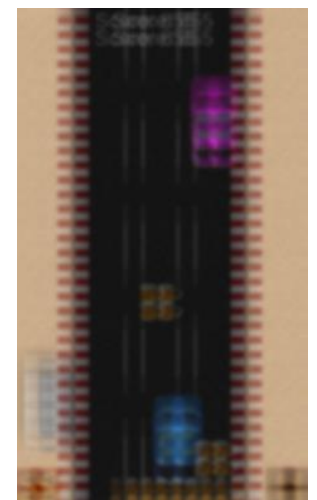

(B)

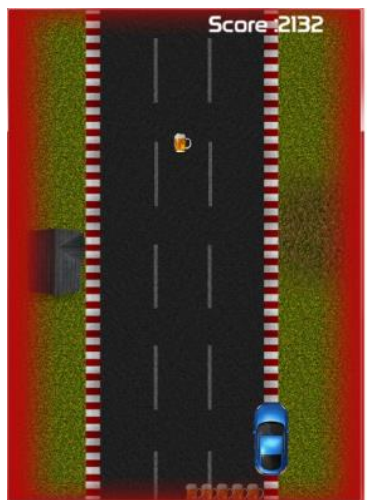

(C)

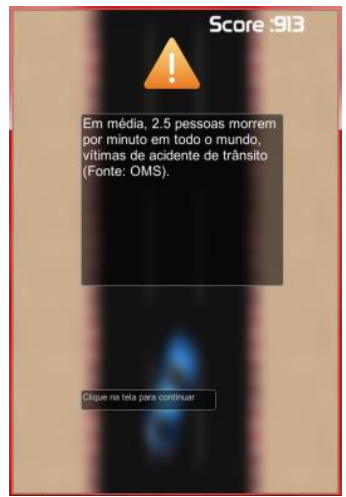

(D)

Figura 1. Telas do jogo "Trânsito Consciente"

Durante o seu trajeto nesta autoestrada, o jogador irá se deparar com alguns "copos de bebida alcóolica" pelo caminho (Figura 1 - A). À medida que o usuário progride no jogo, pode ser que ele passe sobre alguns destes "copos de bebida alcóolica". Quando isto ocorrer, o jogo irá alterar, automaticamente, o tempo de resposta 
para a mudança de direção do veículo. Essa mudança no tempo de resposta simulará a perda de reflexo do motorista por ter consumido alguma quantidade de bebida alcóolica. Esse tempo de resposta vai aumentando até um limite pré-estabelecido, enquanto o jogador estiver "passando sobre mais copos de bebida alcóolica". Outra alteração que ocorre no jogo é o embaçamento da tela do jogo, simulando o efeito de visão dupla causado pelo álcool no organismo humano (Figura 1 - B).

Com o tempo de resposta alterado e com o embaçamento da tela, fica cada vez mais difícil desviar-se dos obstáculos da pista, ou seja, dos outros veículos da estrada, bem como se manter dentro da pista. Uma vez que o jogador venha a colidir com outro veículo ou saia da pista, ele perde e o jogo volta ao início. O desafio proposto ao jogador é tentar conduzir o veículo durante o máximo de tempo possível, se mantendo na pista e desviando-se dos "copos de bebida alcóolica" e dos veículos da estrada, obtendo assim uma maior pontuação (score). Alguns outros elementos apresentados na tela do jogo são (Figura 1 - C): (i) a quantidade de "copos de bebida alcóolica consumidos" pelo motorista é indicada na parte inferior direita da tela; (ii) o score (quantidade de pontos) do jogador é apresentado na parte superior direita da tela; e (iii) quando o veículo do jogador estiver prestes a sair da pista, uma borda vermelha é apresentada ao redor da tela, como forma de aviso de perigo.

A conscientização proporcionada pelo jogo está no fato de o jogador perceber como o álcool ingerido pode influenciar negativamente o reflexo e a visão de um motorista, aumentando significativamente as chances de que um acidente ocorra. Além disso, quando o jogador perde, uma dentre várias mensagens de conscientização para educação no trânsito é exibida na tela, conforme pode ser observado na Figura 1 - D.

\subsection{Trabalhos Relacionados}

Uma iniciativa semelhante ao jogo "Trânsito Consciente" são os simuladores de trânsito disponibilizados por algumas autoescolas. Estes simuladores possuem um módulo interativo, no qual o candidato a motorista configura a quantidade de copos de bebida alcoólica ingeridos antes de assumir a direção do veículo e o software simula sensações comuns aos indivíduos que dirigem sob o efeito de álcool. Um dos fatores que impedem a ampla utilização deste recurso pode ser o seu alto custo de aquisição, que fica em torno de R $\$ 40$ mil. Outra limitação de tais simuladores é quantidade de recursos necessários para utilização dos mesmos (em geral, são três monitores grandes e hardwares específicos como volantes, pedais, entre outros), o que os torna bem menos portátil do que um dispositivo móvel, como um smartphone. Uma diferença importante do jogo "Trânsito Consciente" em relação aos simuladores de trânsito é a sua abrangência, uma vez que o mesmo pode ser utilizado por qualquer indivíduo que possua um dispositivo móvel com a plataforma Android.

\section{Avaliação do Jogo "Trânsito Consciente"}

\subsection{Planejamento}

Para que a avaliação de qualquer tecnologia seja efetiva, torna-se necessário observar os objetivos a serem alcançados com tais medições. Neste sentido, uma abordagem comumente utilizada para avaliação de produtos, processos e serviços é a GQM (GoalQuestion-Metrics) (Basili e Rombach, 1994).

A abordagem GQM baseia-se na premissa de que para avaliar qualquer tecnologia (como por exemplo, um jogo), primeiramente deve-se conhecer os objetivos 
desta avaliação. GQM é dividida em três níveis (Basili e Rombach, 1994): (i) Conceitual: nível no qual são definidos os objetivos da avaliação - o objetivo é definido para um objeto que será avaliado (produto, processo, serviço, entre outros); (ii) Operacional: nível no qual são definidas questões para caracterizar um caminho para se alcançar um determinado objetivo; e (iii) Quantitativo: nível no qual são definidas as métricas que associam um conjunto de dados quantitativos com cada questão elencada, possibilitando assim, que as mesmas possam ser devidamente respondidas.

Para o modelo de avaliação do jogo "Trânsito Consciente" foram criados dois objetivos, os quais são apresentados no Quadro 1.

Quadro 1. Objetivos de Avaliação do jogo "Trânsito Consciente"

\begin{tabular}{|c|c|}
\hline OBJETIVO DE AVALIAÇÃO 1 & OBJETIVO DE AVALIAÇÃO 2 \\
\hline Analisar o: jogo "Trânsito Consciente" & Analisar o: jogo "Trânsito Consciente" \\
\hline Com o propósito de: avaliar & Com o propósito de: avaliar \\
\hline Com respeito à: utilidade percebida & Com respeito à: facilidade de uso percebida \\
\hline Do ponto de vista dos: jogadores & Do ponto de vista dos: jogadores \\
\hline $\begin{array}{l}\text { No contexto: dos indivíduos da comunidade de } \\
\text { Jataí/GO. }\end{array}$ & $\begin{array}{l}\text { No contexto: dos indivíduos da comunidade de } \\
\text { Jataí/GO. }\end{array}$ \\
\hline
\end{tabular}

A partir desses objetivos, algumas questões foram elencadas a fim de que, uma vez respondidas, pudessem indicar se os objetivos de avaliação foram atingidos ou não: (i) questão referente ao objetivo 1 - a maioria dos avaliadores do jogo "Trânsito Consciente" concorda que o mesmo é útil para conscientização da população com respeito aos riscos de se dirigir sob efeito de álcool?; e (ii) questão referente ao objetivo 2 - a maioria dos avaliadores do jogo "Trânsito Consciente" concorda que o mesmo é fácil de se utilizar?

Uma vez definidas as questões para cada objetivo de avaliação, faz-se necessário especificar um conjunto de métricas capazes de indicar valores que, quando interpretados, fornecerão as informações necessárias para que o pesquisador responda estas questões. Para responder às questões destacadas anteriormente, o modelo de aceitação de tecnologia TAM (Technology Acceptance Model) (Davis et al., 1989) foi utilizado. Esse modelo possui como objetivo explicar o comportamento das pessoas em relação à aceitação de uma tecnologia. O modelo TAM define dois constructos básicos (Davis et al., 1989): (i) utilidade percebida, que mede o quanto uma pessoa acredita que uma tecnologia é útil para determinada finalidade; e (ii) facilidade de uso percebida, que mede o quanto uma pessoa acredita que o uso de determinada tecnologia é fácil.

Para isso, o modelo TAM sugere a criação de questionários, aos quais são atribuídas afirmações relacionadas à facilidade de uso e utilidade da tecnologia em análise. Para cada afirmação, o respondente (avaliador) poderá escolher uma dentre as seguintes opções "Discordo Totalmente", "Discordo Parcialmente", "Indiferente", "Concordo Parcialmente" e "Concordo Totalmente", conforme sua opinião sobre esta afirmação.

As métricas utilizadas para a avaliação do jogo "Trânsito Consciente" referem-se à porcentagem de avaliadores que escolheram cada uma das alternativas possíveis para as afirmações dos questionários (por exemplo, PDT refere-se à Porcentagem de pessoas que Discordam Totalmente de determinada afirmação, PCP consiste na Porcentagem de pessoas que Concordam Parcialmente sobre determinada afirmação, assim sucessivamente). Uma etapa importante do nível quantitativo do modelo GQM é 
especificar a interpretação das métricas de cada questão. Neste caso, como todas as afirmações do questionário aplicado nesta avaliação são positivas a respeito das características do jogo, quanto maior a porcentagem de avaliadores que escolheram as opções "Concordo Totalmente" e "Concordo Parcialmente", melhor. A partir desta interpretação, é possível elencar hipóteses a fim de se extrair conclusões a partir dos resultados obtidos com a avaliação do jogo. Foram elencadas 4 (quatro) hipóteses, que podem ser observadas nos Quadros 3 e 4.

\section{Quadro 3. Hipóteses relacionadas à utilidade percebida}

\begin{tabular}{|c|l|}
\hline $\begin{array}{c}\mathrm{HU}_{0} \\
\text { (hip. nula) }\end{array}$ & $\begin{array}{l}\text { Não há diferença entre a proporção de avaliadores do jogo "Trânsito Consciente" que } \\
\text { concordam que o mesmo seja útil para conscientização da população com respeito aos riscos } \\
\text { de se dirigir sob efeito de álcool e a proporção de avaliadores que não concordam com esta } \\
\text { afirmação? Em outras palavras, PDT + PDP = PCP + PCT. }\end{array}$ \\
\hline $\begin{array}{c}\mathrm{HU}_{1} \\
\text { (hip. alternativa) diferença entre a proporção de avaliadores do jogo "Trânsito Consciente" que } \\
\text { concordam que o mesmo seja útil para conscientização da população com respeito aos riscos } \\
\text { de se dirigir sob efeito de álcool e a proporção de avaliadores que não concordam com esta } \\
\text { afirmação? Em outras palavras, PDT + PDP } \neq \text { PCP + PCT. }\end{array}$ \\
\hline
\end{tabular}

\section{Quadro 4. Hipóteses relacionadas à facilidade de uso percebida}

\begin{tabular}{|c|l|}
\hline $\begin{array}{c}\mathrm{HFU}_{0} \\
\text { (hip. nula) }\end{array}$ & $\begin{array}{l}\text { Não há diferença entre a proporção de avaliadores do jogo "Trânsito Consciente" que } \\
\text { concordam que o mesmo seja fácil de usar e a proporção de avaliadores que não concordam } \\
\text { com esta afirmação? Em outras palavras, PDT + PDP= PCP + PCT. }\end{array}$ \\
\hline $\begin{array}{c}\text { HFU } \\
\text { (hip. alternativa) }\end{array}$ & $\begin{array}{l}\text { Há diferença entre a proporção de avaliadores do jogo "Trânsito Consciente" que } \\
\text { concordam que o mesmo seja fácil de usar e a proporção de avaliadores que não concordam } \\
\text { com esta afirmação? Em outras palavras, PDT + PDP \# PCP + PCT. }\end{array}$ \\
\hline
\end{tabular}

O Quadro 3 apresenta as hipóteses relacionadas à utilidade percebida pelos avaliadores com respeito ao jogo "Trânsito Consciente", a saber, $\mathrm{HU}_{0}$ e $\mathrm{HU}_{1}$. O Quadro 4 apresenta as hipóteses relacionadas à facilidade de uso do jogo percebida pelos avaliadores, isto é, $\mathrm{HFU}_{0}$ e $\mathrm{HFU}_{1}$.

\subsection{Execução e Análise dos Resultados}

O jogo "Trânsito Consciente" foi avaliado por 38 (trinta e oito) indivíduos entre 12 (doze) e 39 (trinta e nove) anos de idade, em um período de uma semana. As questões do questionário de avaliação, bem como a porcentagem de avaliadores que escolheu cada uma das opções disponíveis no mesmo foi sumarizada no Quadro 5.

As afirmações dos questionários de avaliação que tiveram maiores porcentagens de avaliadores que não concordaram com as mesmas foram: "Os elementos da interface gráfica do jogo 'Trânsito Consciente' possuem design moderno e atraente", "É fácil conhecer e entender as regras do jogo "Trânsito Consciente'." e "As penalidades e os desafios do jogo 'Trânsito Consciente' estão claros.". Isso é um indício de que jogo precisa passar por um processo de manutenção, com o intuito de aprimorar a qualidade dos elementos gráficos do mesmo, bem como elaborar elementos explicativos mais sugestivos sobre as regras e desafios do jogo.

Por outro lado, as duas afirmações mais bem aceitas pelos avaliadores foram “Utilizar o jogo 'Trânsito Consciente' pode auxiliar na conscientização da população a respeito dos riscos de dirigir sob efeito de álcool." e "Além da parte da conscientização, o 'Trânsito Consciente' permite ao jogador se divertir enquanto o joga.". Isso indica que, apesar dos problemas de interface e da deficiência na explicação do funcionamento do jogo, os avaliadores conseguiram compreender o enfoque de conscientização do mesmo, além de terem se divertido enquanto o jogavam. 
CBIE-LACLO 2015

Anais do XXI Workshop de Informática na Escola (WIE 2015)

Apesar de os valores apresentados no Quadro 5 indicarem visualmente que há indícios de aceitação das características de utilidade e facilidade de uso do jogo "Trânsito Consciente" por parte dos avaliadores do mesmo, faz-se necessário realizar a análise estatística dos dados, por meio de testes de hipóteses, com o intuito de garantir maior confiabilidade às afirmações feitas. O Quadro 7 apresenta a quantidade de respostas do tipo "Discordo parcial ou totalmente", "Concordo parcial ou totalmente" e "Indiferente" para cada constructo analisado.

Quadro 5. Afirmações relacionadas à utilidade percebida

\begin{tabular}{|c|c|c|c|}
\hline & & & erceb \\
\hline $5 \%$ & $5 \%$ & $26 \%$ & $64 \%$ \\
\hline
\end{tabular}

\begin{tabular}{|c|c|c|}
\hline $3 \% \quad 3 \%$ & $29 \%$ & $65 \%$ \\
\hline
\end{tabular}

\begin{tabular}{|l|c|c|c|}
\hline $\mathbf{3 \%}$ & $\mathbf{3 \%} \%$ & $\mathbf{5 \%}$ & $\mathbf{7 3 \%}$ \\
\hline O jogo "Trânsito Consciente" apresenta informações úteis sobre os impactos do uso de álcool no trânsito. \\
\hline
\end{tabular}

\begin{tabular}{|l|l}
$5 \%$ & $\mathbf{2 9 \%}$ \\
\hline
\end{tabular}

Além da parte da conscientização, o "Trânsito Consciente" permite ao jogador se divertir enquanto o joga.

\begin{tabular}{|c|c|c|c|c|}
\hline $8 \%$ & $5 \%$ & $16 \%$ & \multicolumn{2}{|l|}{$71 \%$} \\
\hline \multicolumn{5}{|c|}{ Eu recomendarei o jogo "Trânsito Consciente" a outros jogadores. } \\
\hline \multicolumn{5}{|c|}{ Afirmações relacionadas à facilidade de uso percebida } \\
\hline $5 \%$ & $11 \%$ & $13 \%$ & $\mathbf{5 0 \%}$ & $21 \%$ \\
\hline
\end{tabular}

\begin{tabular}{|c|c|c|c|}
\hline \begin{tabular}{|l|l|}
$5 \%$ & $3 \%$
\end{tabular} & $13 \%$ & $21 \%$ & $58 \%$ \\
\hline
\end{tabular}

\begin{tabular}{|c|c|c|c|c|}
\hline $\mathbf{5 \%}$ & $\mathbf{5 \%}$ & $\mathbf{3 \%}$ & $\mathbf{2 4 \%}$ & $\mathbf{6 3 \%}$ \\
\hline
\end{tabular}

\begin{tabular}{|c|c|c|c|c|}
\hline $5 \%$ & $11 \%$ & $8 \%$ & $21 \%$ & $55 \%$ \\
\hline
\end{tabular}

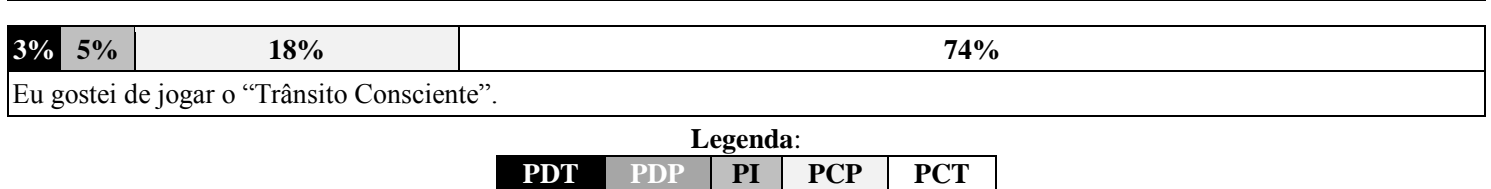

Estes valores foram obtidos contando a quantidade de respostas de cada tipo para todas as afirmações de um determinado construto. Como havia trinta e oito avaliadores e cinco questões para cada constructo, então a quantidade de observações total por constructo é de 190 (cento e noventa).

Quadro 7. Quantidade de observações por constructo

\begin{tabular}{|c|r|r|r|r|}
\hline Tipos de Observação & \multicolumn{2}{|c|}{ Utilidade } & \multicolumn{2}{c|}{ Facilidade de Uso } \\
\hline & \multicolumn{1}{|c|}{ Obs. } & \multicolumn{1}{c|}{$\boldsymbol{\text { Obs. }}$} & \multicolumn{1}{c|}{$\%$} \\
\hline Discordam parcial ou totalmente (PDP ou PDT) & 10 & 5,3 & 20 & 10,5 \\
\hline Concordam parcial ou totalmente (PCP ou PCT) & 173 & 91,0 & 154 & 81,0 \\
\hline Não concordam, nem discordam (indiferente) (PI) & 7 & 3,7 & 16 & 8,5 \\
\hline Total de Observações & $\mathbf{1 9 0}$ & $\mathbf{1 0 0}$ & $\mathbf{1 9 0}$ & $\mathbf{1 0 0}$ \\
\hline
\end{tabular}

O objetivo de um teste de hipótese é verificar se uma hipótese nula (por exemplo, $\mathrm{HFU}_{0}$ ou $\mathrm{HU}_{0}$ ) pode ser rejeitada com algum grau de significância (confiança 
de que está se tomando a decisão correta), chegando assim, à aceitação da hipótese alternativa (por exemplo, $\mathrm{HFU}_{1}$ ou $\mathrm{HU}_{1}$ ). Sendo assim, para testar as hipóteses dos Quadros 3 e 4, realizou-se a aplicação do teste conhecido como Chi-quadrado (Chisquare) (Montgomery, 2000). O teste Chi-quadrado é aplicado quando se deseja saber se dois grupos diferem significativamente a respeito de uma/um determinada característica/aspecto. Por exemplo, por meio desse teste é possível saber se o grupo de pessoas que concordam que uma determinada tecnologia é útil é proporcionalmente diferente do grupo que não concorda. A hipótese nula deste teste afirma que as proporções dos dois grupos de dados são iguais.

O teste Chi-quadrado foi aplicado ao conjunto de dados obtido, comparando os valores médios da proporção de avaliadores que concordaram parcialmente ou totalmente (PCP ou PCT) a respeito das afirmações relacionadas à utilidade e à facilidade de uso percebidas versus os valores médios da proporção de avaliadores que não concordaram parcialmente ou totalmente (PDP ou PDT), conforme apresentado no Quadro 7. Para os propósitos deste estudo avaliativo, utilizou-se o menor grau de significância possível para rejeitar a hipótese nula do teste Chi-quadrado. Além disso, o maior grau de significância aceito para rejeitar a hipótese nula proposta neste trabalho foi de $5 \%(p=0.05)$, ou seja, a hipótese nula só será considerada rejeitada com um grau de confiança maior ou igual a $95 \%$.

Após a aplicação do teste Chi-quadrado, as hipóteses nulas $\mathrm{HU}_{0}$ e $\mathrm{HFU}_{0}$ puderam ser rejeitadas com grau de significância $p$-value $<0,0001$. Ou seja, com aproximadamente $99,99 \%$ de confiança, é possível afirmar que há diferença entre a proporção de avaliadores do jogo "Trânsito Consciente" que concordam que o mesmo seja útil e fácil de usar e a proporção de avaliadores que não concordam com esta afirmação. Além disso, como a proporção de avaliadores que concordaram totalmente ou parcialmente (91\% para o constructo utilidade percebida e $81 \%$ para facilidade de uso percebida) é maior do que a proporção média dos que não concordaram parcialmente ou totalmente $(5,3 \%$ para o constructo utilidade percebida e $10,5 \%$ para facilidade de uso percebida), há indícios de que o jogo "Trânsito Consciente" seja útil e fácil de se utilizar e que as questões relacionadas ao objetivo de avaliação 2 podem ser respondidas positivamente.

\subsection{Ameaças à Validade}

Segundo Wholim et al. (2012), um estudo experimental está sujeito a situações que podem ameaçar a validade dos resultados obtidos a partir deste estudo. As principais ameaças tratadas neste estudo são:

Validade de Conclusão. Refere-se às questões que afetam a habilidade de tirar conclusões corretas a respeito do objeto de estudo do experimento. Um exemplo de ameaça deste tipo diz respeito à escolha do método estatístico adequado para análise dos dados. No caso deste estudo, um dos testes estatísticos adotado foi o Chi-quadrado. Este teste foi escolhido por ser não-paramétrico, isto é, ele permite que duas proporções sejam comparadas, sem a necessidade de os dados que a geraram estarem distribuídos normalmente.

Validade Interna e Externa. Refere-se às questões que afetam a habilidade de assegurar que os resultados não foram obtidos em decorrência de uma coincidência e que os mesmos podem ser generalizados para um contexto mais amplo do que foi selecionado para o estudo. Sendo assim, o principal fator que pode ter influenciado nos 
resultados deste experimento é a falta de clareza das afirmações do questionário apresentado aos avaliadores, que pode ter gerado interpretações ambíguas. Com o intuito de mitigar essas possíveis ameaças, pretende-se replicar tal experimento com outros grupos de participantes.

\section{Considerações Finais}

O crescente aumento do número de veículos nas cidades e, consequentemente, do número de acidentes de trânsito, apresenta uma demanda por estratégias que possam vir minimizar tal problema. Este trabalho apresentou um jogo, denominado "Trânsito Consciente", cujo intuito é conscientizar indivíduos dos riscos de se dirigir sob o efeito de álcool. Tal jogo foi desenvolvido para a plataforma móvel Android, permitindo sua execução em diversos tipos de aparelhos, tais como smartphones e tablets. A partir da avaliação realizada com o jogo "Trânsito Consciente", constatou-se que os avaliadores concordam quanto à utilidade e à facilidade de uso do mesmo, apesar de terem destacado limitações, principalmente, quanto aos aspectos de qualidade dos elementos gráficos e instrucionais do jogo.

Como propostas de trabalhos futuros, pretende-se implementar: (i) novos tipos de efeitos no jogo, relacionados a outras sensações provenientes da ingestão de álcool, como irritabilidade, entre outros; (ii) outros tipos de obstáculos e provas que devem ser cumpridas no jogo, como por exemplo, passar por um circuito delimitado por cones de sinalização; (iii) diferentes "tipos de bebidas alcóolicas" no jogo, a fim de se evidenciar o maior potencial embriagador de algumas bebidas com relação a outras; (iv) o jogo "Trânsito Consciente" para outras plataformas móveis, como iOS e Windows Phone; e (v) novas funções que atuem na conscientização do motorista com relação a outras atitudes prejudiciais no trânsito, tais como falar ao telefone, dirigir em alta velocidade, entre outros.

\section{Referências}

Annetta, L. "The 'I's' have it: a framework for serious educational game design". In: Review of General Psychology, 2010.

Basili, V.; Rombach, H. "Goal question metric paradigm”. In: Encyclopedia of Software Engineering, v. 2, 1994.

CEITC.br - Centro de Estudos sobre as Tecnologias da Informação e da Comunicação. "Pesquisa sobre o Uso das Tecnologias de Informação e Comunicação no Brasil". Disponível em: http://www.cetic.br/usuarios/tic/2012/ index.htm. Acessado em: Maio/2015.

CISA - Centro de Informações sobre Álcool e Saúde. Álcool e Trânsito. Disponível em: http://www.cisa.org.br/ artigo/382/alcool-transito.php. Acessado em: Maio/2015.

CET - Companhia de Engenharia de Tráfego de São Paulo. "Relatório Anual de 2012”. Disponível em: http://www. cetsp.com.br/media/234481/relatorioanual2012.pdf. Acessado em: Maio/2015.

CONTRAN - Conselho Nacional de Trânsito. "Resoluções do CONTRAN". Disponível em: http://www.denatran. gov.br/resolucoes.htm. Acessado em: Maio/2015.

Davis, F. D.; Bagozzi, R. P.; Warshaw P. R. "User Acceptance of Computer Technology: A Comparison of two Theoretical Models". In: Management Science. v. 35(8), p. 982-1003, 1989.

Fernandes, L.; Werner, C. "Sobre o uso de jogos digitais para o ensino de engenharia de software". In: Simpósio Brasileiro de Engenharia de Software, 2009.

Maio Amarelo. Projeto Maio Amarelo: Atenção pela Vida. Disponível em: http://maioamarelo.com/pagina/ movimento. Acessado em: Maio/2015.

Mitchell, A.; Savill-Smith, C. "The use of computer and video games for learning: A review of the literature". In: Londres: Learning and Skills Development Agency (LSDA), 2004.

Montgomery, D. C. Design and Analysis of Experiments, $5^{\text {a }}$ ed., Wiley, 2000.

Ravagnani, N. A. T. "O uso do álcool e a direção veicular". Monografia de Especialização em Psicologia no Trânsito. Centro Universitário de Araras - UNAR, Araras/SP, 2010.

Savi, R.; Ulbricht, V. R. "Jogos digitais educacionais: benefícios e desafios”. In: Novas Tecnologias na Educação, 2010.

Wholin, C. et al. Experimentation in Software Engineering: an introduction. Springer. 249 p, 2012. 